\title{
Um modelo de fluxo informacional para empresas do setor de confecção
}

\section{An information flow model for product planning in the clothing industry}

\author{
Letícia Cunico, Instituto Federal de Educação, Ciência e Tecnologia de Santa \\ Catarina. \\ leticia.cunico@ifsc.edu.br
}

Claudelino Martins Dias Junior, Universidade Federal de Santa Catarina. claudelino.junior@ufsc.br

\begin{abstract}
Resumo
As empresas que trabalham orientadas para o consumidor são pressionadas a buscar inovações constantes e em curtos prazos para o lançamento de novos produtos. Assim, para se tornarem competitivas, empregam processos e ferramentas que possibilitem qualificar informações na tomada de decisão. Desta forma, percebe-se que o fluxo informacional tem se tornado objeto de atenção dentro do Processo de Desenvolvimento de Produto (PDP). Nesse sentido, o objetivo deste estudo centra-se na proposição de um fluxo informacional que oriente o planejamento de produto em empresas do setor de confecção, visando mais assertividade na determinação de portfólios e capacidade de resposta comercial. Busca-se simplificar a aplicação de conceitos amplos e sinalizar a importância de atender às expectativas do consumidor nas trocas de informações entre a equipe de produto e a área comercial.
\end{abstract}

Palavras-chave: Fluxo informacional, Setor de confecção, Planejamento de produto, Gestão do produto

\begin{abstract}
Consumer-oriented companies are frequently under pressure to seek constant innovation, on short-term new product launches, employing processes and tools that qualify information for fast decision making. Therefore, information flow has become a valuable object of attention within the Product Development Process (PDP). This study proposes an information flow model that guides product planning for companies of the clothing industry, contributing for effective portfolio choices and agile commercial responses. It is aimed at simplifying the application of broad concepts, as well as bringing to light the importance of attending to consumer expectations on information exchanges between product and commercial teams.
\end{abstract}

Keywords: Information flow, Clothing industry, Product planning, Management Product 


\section{Introdução}

O setor têxtil e de confecção, segundo (IEMI, 2017), no Brasil alcançou em 2016 um panorama de 29,5 mil empresas com mais de 5 (cinco) empregados e, 1,5 milhão de empregos diretos. Dada a necessidade de inovar produtos e processos, a indústria prioriza novos aspectos como o design e o uso de tecnologia para alinhar-se à demanda dos consumidores em quantidade e qualidade de produtos ou serviços que eles desejem adquirir. Especificamente, para produtos ligados ao vestuário e à moda, além da exigência nas variáveis custo e qualidade, o cliente busca estilo, novas tendências e conforto.

Assim, as empresas que trabalham orientadas ao mercado são pressionadas a satisfazer seus desejos, em prazos curtos de entrega de forma a diferenciar-se de seus concorrentes (LIBÂNIO; AMARAL, 2017). Além disso, a oferta de novos produtos exige o emprego de processos e ferramentas eficientes; portanto, "um forte sistema de desenvolvimento de produto é uma competência central fundamental para o sucesso de qualquer companhia voltada ao consumidor" (MORGAN; LIKER, 2008, p. 26).

Nesse contexto, segundo Shankar et al. (2013), o acompanhamento das informações geradas no ambiente interno e no ambiente externo das organizações determinam a competitividade da empresa. Informações podem ser definidas, como dados utilizáveis, descrições ou inferências, alicerçando os processos organizacionais. Para Cunha, Pereira e Neves (2015), informações são consideradas recursos, os quais são necessários em todos os níveis organizacionais.

Da necessidade de organizar e compartilhar tais informações surge o fluxo informacional (CUNHA; PEREIRA; NEVES, 2015), que é determinado por uma rede de atividades executadas por uma rede de pessoas (PARRAGUEZ; EPPINGER; MAIER, 2015). Sim e Duffy (2003) definem atividade como a ação real de executar uma tarefa de projeto, transformando informações input (de entrada) em informações output (de saída).

Neste sentido, propõe-se aqui que os esforços devem se concentrar na concepção de modelo de fluxo informacional que possa dar mais capacidade de resposta às equipes de desenvolvimento de produto e à área comercial em empresas de pequeno porte no setor de confecção. Utilizar um fluxo informacional bem delineado entre os envolvidos no PDP é uma das formas de alcançar a otimização de tempo, essencial para a indústria de confecção. Segundo Parraguez, Eppinger e Maier (2015), para estudar o fluxo informacional, deve-se estar alicerçado, primeiramente, em um modelo de PDP.

Para que o conhecimento seja denominado como científico ou acadêmico é necessário que seu desenvolvimento esteja pautado em regras e procedimentos. Dessa forma, este estudo valese do método dedutivo, tendo-se por referência um constructo conceitual e teórico, preconizado por Lakatos e Marconi (2014). A forma de abordagem é qualitativa, de natureza aplicada e, quanto aos objetivos, descritiva. 


\section{Planejamento de Produto}

O planejamento de produto é a fase inicial de trabalho de um projeto de produto. Isso é definido pelo processo de identificação e seleção de ideias com o intuito de desenvolver novos produtos através de atividades, métodos e ferramentas específicas (BACK et al., 2008).

O ponto central do planejamento do produto está em, após entender o desejo do consumidor, decidir quando e quais produtos serão desenvolvidos. Para isso, realiza-se um estudo de mercado para verificar a consistência do produto que se pretende oferecer com determinado nível de qualidade e inovação, alinhado ao que o consumidor deseja e às possíveis vantagens que ele terá ao adquiri-lo (TONOLLI JUNIOR; BRODBECK; COSTA, 2012). Neste sentido, o profissional de design de moda encontra-se em um processo de fazer sentido a produtos de curto prazo, mas também a expressões culturais no cenário de longo prazo em um ambiente de tendências, incertezas e descontinuidades (ROUBELAT et al., 2015 apud PEDRONI, 2013; SCHWARTZ, 1991; WRIGHT \& CAIRNS, 2011)

Portanto, entender o desejo do consumidor é o primeiro passo. Em seguida, deve-se buscar informações sobre como operacionalizar tais produtos. Por essa via, realiza-se um estudo de viabilidade técnica e econômica do produto e uma análise que verifica se a estrutura organizacional é capaz de produzi-lo ou se há necessidade de terceirizar etapas do processo de produção, por exemplo.

O planejamento de produtos levanta dados do usuário, suas necessidades e possibilidades a serem exploradas, para transformá-las em requisitos do usuário, que gerarão especificações de projeto, para possibilitar o desenvolvimento efetivo do produto. Consideram-se aqui como usuários os consumidores, os colaboradores e os stakeholders (PARRAGUEZ; EPPINGER; MAIER, 2015).

$\mathrm{Na}$ fase de especificação de projeto, expõe-se o problema fazendo uma descrição funcional, quantitativa e qualitativa, formalizando o projeto, construindo uma base de critérios para avaliar a tomada de decisão das próximas etapas, o que possibilita o desdobramento funcional e o planejamento das atividades do projeto de produtos (BACK et al., 2008).

\section{PDP em Empresas do Setor da Confecção}

Conforme Rech (2006, p. 72), coleção é um "conjunto de produtos, com harmonia do ponto de vista estético ou comercial, cuja fabricação e entrega são previstas para determinadas épocas do ano". Segundo Treptow (2013), uma coleção coerente deve contemplar os seguintes elementos: perfil do consumidor, identidade da marca, tema da coleção e proposta de cores, materiais e silhuetas. Além disso, Treptow (2013) destaca que uma coleção de produtos de confecção coerente exige uma metodologia de processo de produto adequada. A aplicação dos métodos resulta em produtos de mais aceitação pelo consumidor, melhor aproveitamento do tempo e melhor desenvolvimento da confecção do produto.

Para Moretti (2012), os inputs para essa fase são: planejamento estratégico da empresa, lista de pessoal e suas competências, além dos dados de coleções passadas. Os posicionamentos definidos pela Alta Gerência através das estratégias de produção, marketing e vendas servirão 
de guia para todas as decisões que serão tomadas no desenvolvimento do produto. As informações geradas nessa fase são documentadas, e, segundo Moretti (2012), os outputs gerados para a fase seguinte são:

a) Equipe de trabalho para a coleção;

b) Lista de atividades;

c) Cronograma da coleção;

d) Indicadores de desempenho;

e) Segmento de trabalho;

f) Público alvo com definição do volume de produção e vendas, pontos de venda e estimativa de orçamento da coleção.

A próxima fase é o planejamento do portfólio da coleção, em que se definem as peças que serão desenvolvidas com base no Mix de produtos, no qual constam informações de grade de tamanho, tipo de peça e quantidade. Na sequência, está a Pesquisa de tendências. No Quadro 1, estão tais fases, correspondendo às fases iniciais do PDPV desenvolvido por Moretti (2012).

\begin{tabular}{|c|c|}
\hline Fase & Atividade \\
\hline \multirow{9}{*}{$\begin{array}{l}\text { Planejamento da } \\
\text { Coleção }\end{array}$} & Definir equipe \\
\hline & Definir atividades e sequência \\
\hline & Preparar cronograma \\
\hline & Definir indicadores de desempenho \\
\hline & Analisar os dados de venda de coleções passadas. \\
\hline & Definir estratégias de produção, marketing e vendas. \\
\hline & Analisar viabilidade econômica da coleção \\
\hline & Gate 1 - Avaliar estratégias para coleção \\
\hline & Preparar plano do projeto \\
\hline \multirow{5}{*}{$\begin{array}{l}\text { Planejamento do } \\
\text { Portfólio de } \\
\text { Produtos }\end{array}$} & Definir grade de tamanhos \\
\hline & Definir tipos de peças a serem desenvolvidas \\
\hline & $\begin{array}{l}\text { Definir a quantidade de peças por modelo e tamanho a serem } \\
\text { desenvolvidas }\end{array}$ \\
\hline & Gate 2-Avaliar grade final \\
\hline & Documentar as decisões tomadas \\
\hline \multirow{7}{*}{$\begin{array}{l}\text { Pesquisa de } \\
\text { mercado }\end{array}$} & Pesquisar tendências de modelos \\
\hline & Pesquisar tendências de tecidos e aviamentos \\
\hline & Pesquisar tendências de cores \\
\hline & Definir especificações de estilo para coleção \\
\hline & Definir tema da coleção \\
\hline & Gate 3 - Avaliar tema \\
\hline & Documentar as decisões tomadas \\
\hline
\end{tabular}

Quadro 1 - Modelo de planejamento do produto segundo Moretti (2012).

Para que essas fases sejam cumpridas com qualidade e rapidez de resposta aos desejos do consumidor, devem ser envolvidas áreas, como Alta Gerência, Gerência de Desenvolvimento do Produto (DP), Comercial, Marketing, Compras, Produção, Qualidade e Engenharia. 
Finardi (2011) analisa o fluxo informacional entre os setores de criação e modelagem em empresas de confecção, mapeando os usuários e as suas fontes de informação. A pesquisa contemplou as pequenas empresas de confecção da Microrregião de Florianópolis (SC).

\section{O Fluxo Informacional no PDP}

Toda organização é formada basicamente por processos de comunicação, com a difusão de informações envolvendo diferentes grupos de pessoas (DURUGBO; TIWARI; ALCOCK, 2013). A aquisição, a organização e o compartilhamento dessas informações no ambiente organizacional tornaram-se ferramentas competitivas no mercado atual (CUNHA; PEREIRA e NEVES, 2015).

O fluxo informacional é determinado por uma rede de atividades executadas por uma rede de pessoas (PARRAGUEZ; EPPINGER; MAIER, 2015). Ela é formada pelos próprios colaboradores e stakeholders que têm acesso a canais de comunicação que facilitam a interação e a sinergia entre grupos de pessoas de dentro e de fora da organização (BURSTEIN; DILLER, 2004).

No planejamento de produto, o fluxo informacional se baseia em dois pilares: no entendimento das necessidades do cliente e na identificação e antecipação das tendências de mercado (BACK et al., 2008). Ademais, o fluxo informacional pode evoluir de forma verbal, escrita ou eletrônica (DURUGBO; TIWARI e ALCOCK, 2013).

Modelo de Jauregui-Becker e Wits (2013)

Jauregui-Becker e Wits (2013) desenvolveram um modelo de fluxo informacional para apoiar o PDP de dispositivos de barbear da empresa PHILIPS. Segundo os autores, o PDP é uma forma de buscar soluções inovadoras para manter uma vantagem competitiva no mercado, desenvolvendo melhores produtos e mais eficientemente. Um diferencial de empresas que alcançam esse patamar é o foco do PDP no fluxo informacional e não apenas nos processos, reagindo às informações sobre clientes, mercados, fornecedores e capacidade de produção de forma contínua.

No material coletado nas entrevistas, identificaram grandes densidades de informação entre fluxos informacionais departamentais. As entrevistas revelaram que o desafio do PDP quanto ao fluxo informacional reside em três pilares: 1) que informação deve ser transmitida? 2) Quando a informação deve ser transmitida? 3) Como deve ser transmitida?

\section{Modelo de Parraguez, Eppinger e Maier (2015)}

Parraguez, Eppinger e Maier (2015) trazem como escopo de seus estudos o projeto de engenharia complexa, no qual o fluxo informacional entre as atividades estão conectados e são progressivamente transformados através dos participantes. É um mapeamento que identifica a interação entre as pessoas até compor uma estrutura de rede unificada. Tudo isso ocorre em uma 
perspectiva de baixo para cima, ou seja, não é uma estrutura imposta no estilo top down (de cima para baixo), mas o simples resultado das relações entre os membros dessa estrutura.

Em sua pesquisa, Parraguez, Eppinger e Maier (2015) seguiram uma sequência para quantificar a rede de informação que explicasse o fluxo informacional de uma empresa, de modo a contribuir para melhorar as etapas de processo. Ao entender o design como um processo social de transformação de informação, Parraguez, Eppinger e Maier (2015) ensinam que, para traçar um fluxo informacional adequado, é necessário coletar os requisitos dos usuários e documentar os pontos que irão satisfazer suas necessidades e expectativas, porque o sucesso de um negócio está intimamente ligado ao atendimento das expectativas do usuário.

\section{Modelo de Moraes e Escrivão Filho (2006)}

O modelo de Moraes e Escrivão Filho (2006) apresenta o processo de gestão da informação, com sua aplicação em empreendimentos industriais de pequeno porte do ramo metalúrgico. Os autores explanam a grande dificuldade que tais empresas enfrentam para utilizar a informação como recurso estratégico e entender quais informações são efetivamente importantes para a tomada de decisão.

Um ponto relevante do estudo está em apresentar duas maneiras de analisar os processos informacionais: uma discutindo o processo principal, ao verificar quais atividades básicas geram demandas de informação; e a outra está em analisar os processos mais específicos dependentes da informação, significa analisar o processo de gerenciamento da informação.

O próximo modelo se refere aos trabalhos desenvolvidos por Durugbo et al. (2012).

Modelo de Durugbo et al. (2012)

Durugbo et al. (2012) apresentam um modelo de fluxo informacional através do Information channel diagrams (ICD), traduzido aqui como Diagrama dos canais de informação. Foi aplicado no cenário de contato de uma empresa do ramo de saúde com o consumidor final. A metodologia para criar o modelo de fluxo informacional estudado por Durugbo et al. (2012) seguem os quatro passos descritos e ilustrados a seguir.

Passo 1 (Figura 1): colocar o nome das equipes dentro do cenário organizacional:

- desenhar algo semelhante a uma piscina de natação para demonstrar as equipes envolvidas;

- dar nome às equipes envolvidas;

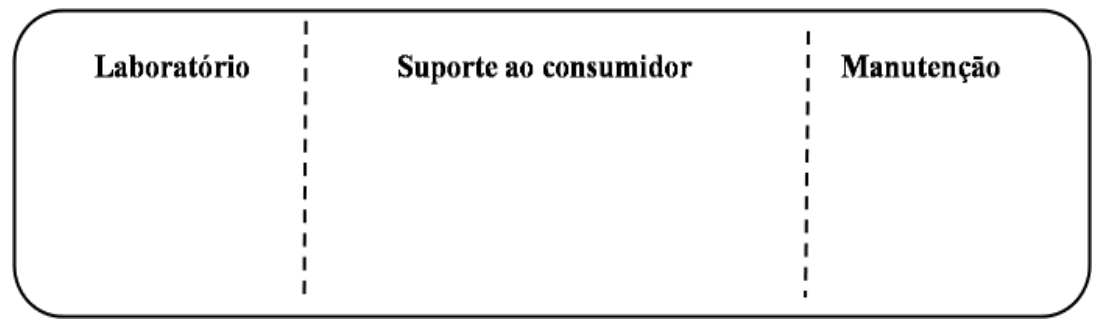

Figura 1 - Passo 1 do modelo de fluxo informacional por Durugbo et al. (2012) 
Passo 2 (Figura 2): posicionar as atividades:

- posicionar as atividades;

- dar nome às atividades;

- incluir o tempo das atividades;

- incluir numeração no retângulo;

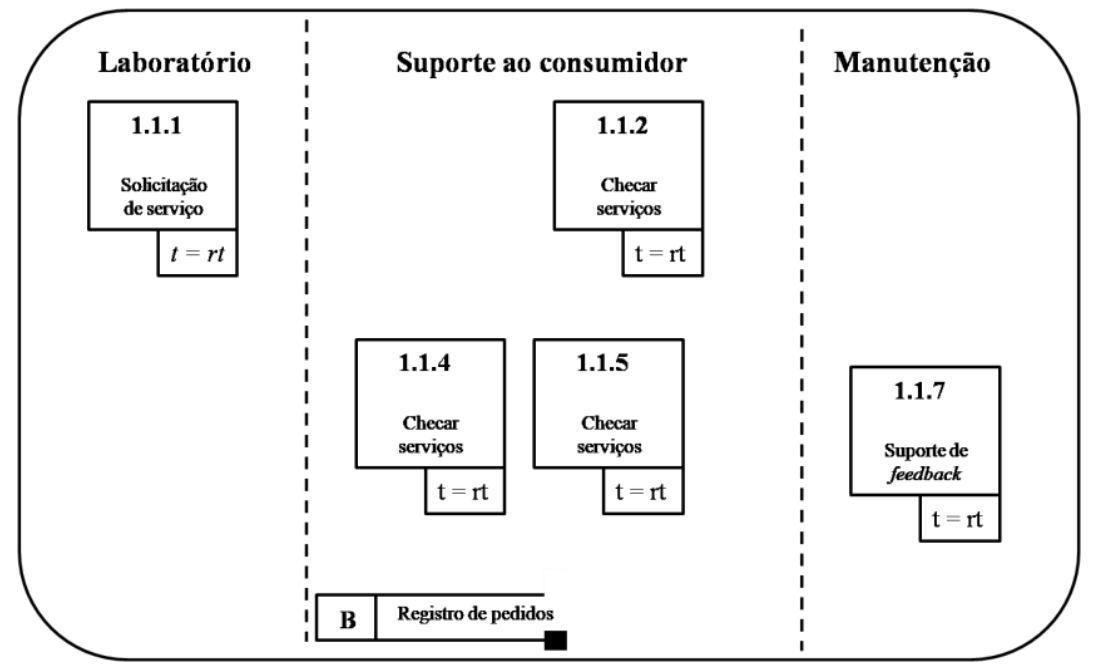

Figura 2 - Passo 2 do modelo de fluxo informacional por Durugbo et al. (2012)

Passo 3 (Figura 3):

introduzir os links do fluxo informacional:

- desenhar os links entre os processos;

- desenhar retângulos com agregação de novas informações ou extração de informações armazenadas;

- descrever o fluxo de informações (nas setas). Acima dos links estão os feed-forward e abaixo os feed-back;

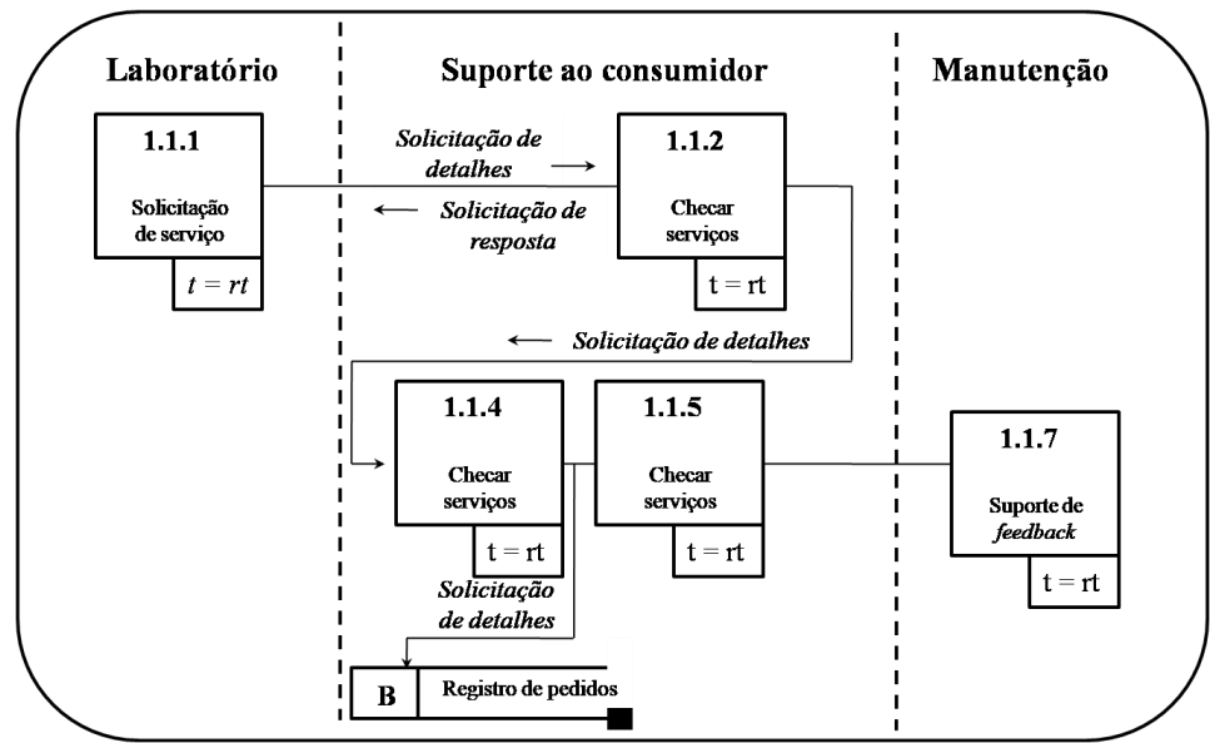


Passo 4 (Figura 4): representar os canais de comunicação:

- representar os canais de comunicações entre os processos, que pode ser sequencial, como o e-mail, por exemplo, ou simultâneo, como uma reunião;

- rever e atualizar.

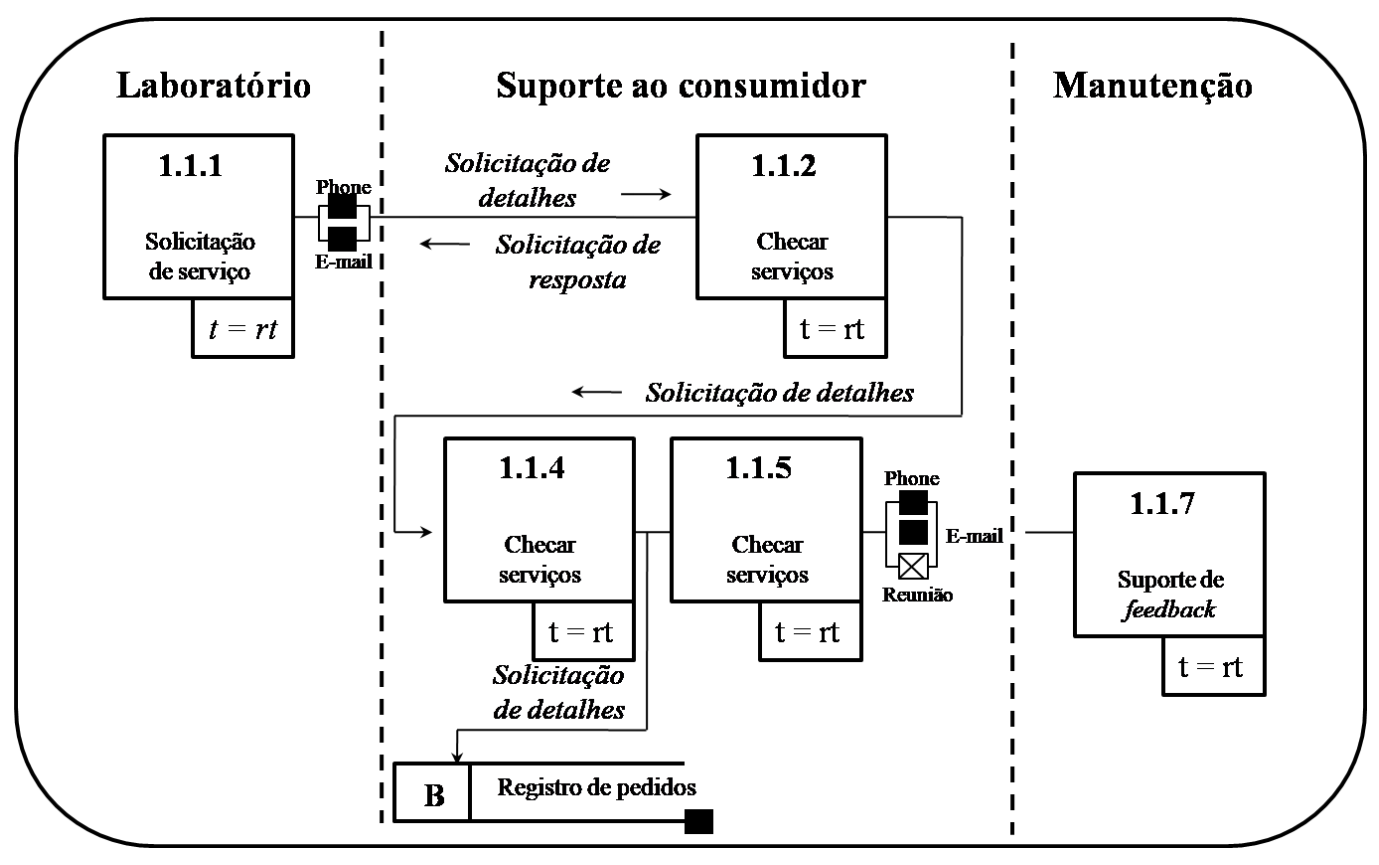

Figura 4 - Passo 4 do modelo de fluxo informacional por Durugbo et al. (2012).

\section{O Modelo Proposto}

Apresenta-se aqui o modelo de fluxo informacional para o planejamento de produto em empresas do setor de confecção adaptado do referencial teórico. Este trecho está organizado com o intuito de descrever de forma genérica o modelo e as etapas de sua elaboração.

\section{Descrição do Modelo}

Parte-se do pressuposto de que o fluxo informacional é dado pelo mapeamento das atividades e dos processos de trabalho dentro de uma transferência contínua de dados entre emissor e receptor, passando por um processo de transformação e consequente geração de conhecimento, segundo a abordagem de Parraguez, Eppinger e Maier (2015), Finardi (2011), Moraes e Escrivão Filho (2006) e Durugbo et al. (2012). Definido o fluxo informacional, espera-se dispor de controle, de melhor capacidade de análise e de consolidação das fontes de informação (Figura 5). 


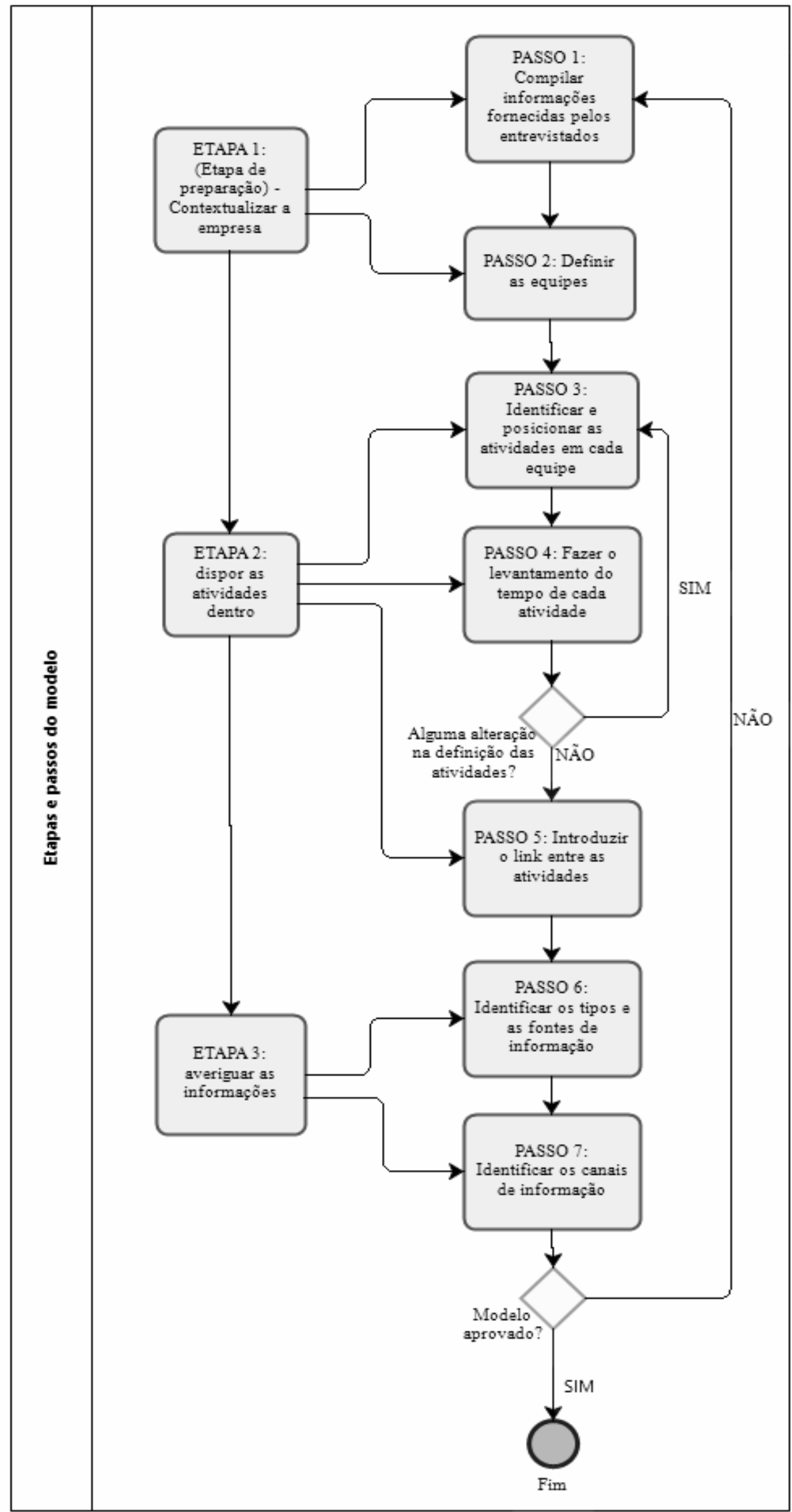

Figura 5 - Etapas e passos do modelo 


\section{Etapas e Passos do Modelo}

Esta seção visa apresentar as etapas e passos referentes ao modelo, especificando o referencial teórico utilizado para construí-lo. Para a modelagem do fluxo informacional e o planejamento de produto no setor de confecção, usam-se diagramas, os quais, segundo Durugbo et al. (2012), são processados de maneira mais eficiente pelos humanos.

A sequência para a modelagem do diagrama de fluxo informacional utilizada por Durubgo et al. (2011) apresenta, de forma clara, os elementos a serem observados na construção de um modelo de fluxo informacional. No presente estudo, utiliza-se o software Bizagi Modeler, através do BPMN (Business Process Modeling Notation) para tal construção.

Na Etapa 1, as informações do planejamento estratégico são os inputs para o planejamento de produto em sua fase conceitual, razão pela qual é necessário um entendimento do contexto no tocante à empresa.

Passo 1 - Compilar as informações fornecidas pelos entrevistados

Esse passo serve para conhecer a situação da organização, ao considerar um breve histórico e seu momento atual, como a quantidade de coleções que a empresa trabalha e de produtos que desenvolve para determinadas épocas do ano (RECH, 2006).

Passo 2 - Definir as equipes

No modelo de fluxo informacional para o planejamento de produto em empresas do setor de confecção, utiliza-se a formação de equipes apontadas por Moretti (2012), em que cinco equipes participam do planejamento de produto: Alta Gerência; Marketing; Equipe de Produto; Comercial e Engenharia. Elas podem relacionar-se com equipes externas para as atividades que envolvem o planejamento de produto.

O modelo de fluxo informacional para o planejamento de produto em empresas do setor de confecção caracteriza-se por uma divisão em "raias" ou "linhas", correspondentes às equipes participantes. A estrutura de "raias" ou "linhas" é extraída dos estudos de Durugbo et al. (2012) e Rodríguez, Fernández-Medina, Piattini (2007), em que se desenha algo semelhante a uma piscina de natação para demonstrar as equipes envolvidas e, posteriormente, dar o nome a elas. Depois de definidos os participantes, são identificadas as atividades convencionalmente desenvolvidas por essas equipes, conforme a Etapa 2.

Na Etapa 2, utilizando-se dos pressupostos de Parraguez, Eppinger e Maier (2015) e Durugbo et al. (2012), tanto a organização, na figura das pessoas, como na arquitetura das atividades por elas executadas no planejamento de produto, precisam ser consideradas para o entendimento da troca de informações. Identificam-se assim, no Passo 3, as atividades desenvolvidas por cada equipe e, o levantamento do tempo de realização de cada atividade no Passo 4. 
Passo 3 - Identificar e posicionar as atividades de cada equipe

Utiliza-se como base os modelos de planejamento de produto de Back et al. (2008), Treptow (2013), Moretti (2012) e Finardi (2011), contando com a relação de atividades e equipes conforme o Quadro 2.

\begin{tabular}{|c|c|}
\hline Atividade & Equipe \\
\hline Fazer levantamento de dados do usuário & \multirow[t]{2}{*}{ Equipe de marketing; } \\
\hline $\begin{array}{l}\text { Transformar o material coletado em } \\
\text { requisitos do usuário }\end{array}$ & \\
\hline Realizar reunião de planejamento & $\begin{array}{l}\text { Equipes de produto, comercial, industrial, } \\
\text { marketing e presidência ou proprietário da } \\
\text { empresa; }\end{array}$ \\
\hline Definir atividades e sequência & Equipe de engenharia e alta gerência; \\
\hline Preparar cronograma & Equipe de engenharia e alta gerência; \\
\hline Verificar a viabilidade produtiva & Equipe de engenharia; \\
\hline $\begin{array}{l}\text { Verificar a viabilidade financeira } \\
\text { (econômica) e comercial }\end{array}$ & Equipe comercial; \\
\hline Desenvolver o mix de produtos & $\begin{array}{l}\text { Equipe de produto, comercial e alta } \\
\text { gerência; }\end{array}$ \\
\hline Fazer pesquisa de tendências e tema & \multirow[t]{2}{*}{ Equipe de produto; } \\
\hline Elaborar briefing ou especificações & \\
\hline
\end{tabular}

Quadro 2 - Relação entre atividades e Equipes.

Passo 4 - Levantamento do tempo de cada atividade

O tempo de execução das atividades referentes ao planejamento de produto depende de algumas definições estratégicas da empresa, como: quantas coleções são desenvolvidas, se a sua venda é por atacado ou varejo, quanto de sua produção depende de fornecedores (CIETTA, 2017). Tendo em mãos a quantidade de coleções e o tempo gasto em cada coleção, pode-se debruçar sobre o tempo empregado nas atividades de planejamento de produto (FINARDI, 2011).

Antes de seguir para a próxima etapa, deve-se verificar se é necessária alguma alteração em relação às atividades. |Se houver, retorna-se para o Passo 3; caso não, consegue-se efetuar o link entre as atividades referentes ao Passo 5.

Passo 5 - Introduzir o link entre as atividades

O Passo 5 está na introdução dos links entre as atividades do fluxo informacional, que consiste no desenho do curso que as atividades seguem dentro do planejamento de produto. Segundo Durugbo et al. (2012), no desenho do fluxo informacional, acima dos links estão as informações que são enviadas à próxima atividade e, quando da necessidade de buscar informações complementares para a execução de uma atividade, essas são representadas por 
retângulos. O software Bizage permite representar as informações que são enviadas à próxima atividade com a simbologia do objeto de dados e buscar informações complementares no depósito de dados.

Passo 6 - Identificar os tipos e as fontes de informação

Para a identificação dos tipos, fontes e canais de informação utilizam-se os modelos de Finardi (2011), Moretti (2012) e Jauregui-Becker e Wits (2013) destacando-se a necessidade de verificar que informações são transmitidas dentro do planejamento de produto. Na Figura 6, são descritos os links, assim como o tipo de informação trocada, representando, portanto, o modelo de fluxo informacional propostos para o planejamento de produto. 
1 EStudos EM DESIGN

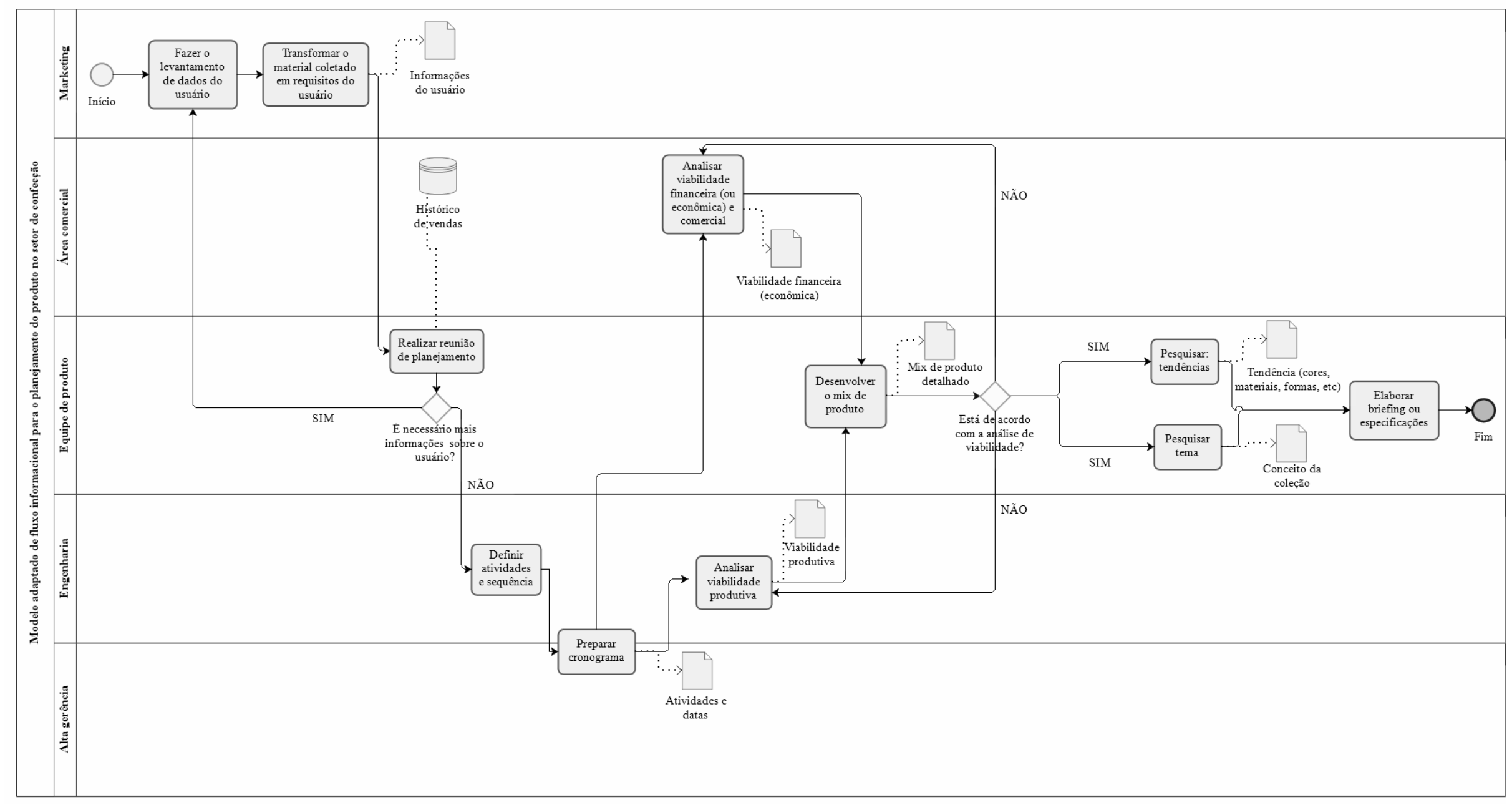

Figura 6 - Modelo de Fluxo Informacional para o planejamento de produto em empresas do setor de confecção. 
O Levantamento de dados do usuário e seus requisitos gera informações utilizadas na construção do Mix de produto. Já para o Cronograma que possibilita orientar toda a cadeia do produto, é necessário acessar informações referentes à compilação das atividades, tanto da Área comercial quanto da Equipe de produto para possibilitar a construção efetiva do Cronograma. Em decorrência, são compartilhadas as informações referentes a quais atividades são desenvolvidas na coleção atual, assim como as datas em que elas devem ser executadas.

O Mix de produto, atividade caracterizada por apresentar a variedade de produtos oferecidos pela empresa, é desenvolvido pela Área comercial em conjunto com a Equipe de produto, valendo-se das informações disponibilizadas pelo Marketing. Uma vez detalhado, o Mix de produto é enviado para a Área comercial e para a Engenharia, para análise de viabilidade econômica, comercial e produtiva, constituindo subsídio para a Alta gerência avaliá-lo e decidir quanto a sua adoção. A Equipe de produto consegue então gerar informações de tendência em consonância com o Mix de produto. Tal equipe realiza também a pesquisa de tema, a partir da qual é gerado o conceito da coleção, culminando com a atividade de Briefing da coleção.

Passo 7 - Identificar os canais de comunicação

Os canais de comunicação - ou seja, as ferramentas que as pessoas utilizam para se relacionar - contribuem para formar a estrutura do fluxo informacional. Através da comunicação, ocorre a interação entre as pessoas; portanto, para ligar a fonte de informações à equipe de planejamento de produto, é importante estabelecer canais de comunicação estruturados.

Para Durugbo, Tiwari e Alcock (2013), o fluxo informacional pode evoluir de forma verbal, escrita ou eletrônica. Nesse estágio, conforme Moraes e Escrivão Filho (2006), é verificado o melhor modo de acessar as informações necessárias.

O Passo 7 consta da identificação dos canais de comunicação entre as atividades, que pode ser sequencial, como o e-mail, por exemplo, ou simultâneo, como uma reunião. Aqui se responde à pergunta de Jauregui-Becker e Wits (2013): como a informação deve ser transmitida?

Uma vez finalizado, o modelo é apresentado para o responsável pelo setor estudado para verificar se há necessidade de melhorá-lo. Caso seja percebida alguma necessidade, retorna-se para o Passo 1 e para os demais passos, para ver se carece de adaptações em função de sua aplicação.

\section{Considerações Finais}

Analisadas as características dos modelos de referência no planejamento do uso da informação no planejamento do produto, percebe-se a escassez de estudos voltados ao setor de confecção. 
Com base no referencial teórico, elencam-se a seguir as atividades que pautam o modelo de fluxo informacional para o planejamento de produto em empresas do setor de confecção: fazer o levantamento de dados do usuário, suas necessidades e possibilidades a serem exploradas; transformar o material coletado em requisitos do usuário; realizar reunião de planejamento; definir atividades e sequência; preparar cronograma; analisar viabilidades (produtiva, econômica e comercial); desenvolver o mix de produto (tipos de peças, grade de tamanho e quantidade de peças); pesquisar tendências, comportamento, mercado, tecnologias, cores, materiais, tema; elaborar briefing ou especificações.

No comparativo entre modelos, são apresentados os elementos necessários para construir um modelo de fluxo informacional: pessoas; atividades; fontes; canais; rede dinâmica; base de comparação; tipo de informação e quando ela deve ser transmitida. A base de comparação decorre tanto da análise de modelos de planejamento de produto quanto da análise dos modelos de fluxo informacional.

Ao referendar o arcabouço teórico, alcança-se o objetivo apresentado inicialmente. No modelo proposto há uma estrutura de equipes completas, de acordo com a teoria, apresentando as cinco equipes participantes já supracitadas: Alta Gerência; Marketing; Equipe de Produto; Comercial e Engenharia.

Ademais, em um cenário de característica dinâmica, devido ao ciclo de lançamento de novos produtos, a empresa do setor da confecção obriga-se a uma atualização constante de sua oferta de produtos, visando à criação de um diferencial competitivo. Para tal, o acompanhamento das informações geradas no ambiente interno e no ambiente externo à organização torna-se um diferencial competitivo. A concepção de um fluxo informacional conciso contribui para a convergência de informação entre as equipes, em especial entre os líderes, de modo a dar mais capacidade de resposta às equipes de desenvolvimento de produto e à área comercial.

Abre-se a possibilidade de um estudo aprofundado do assunto com maior alinhamento das equipes em relação ao planejamento de produto, o que pode trazer contribuições para uma possível redução do lead time e melhor desempenho comercial, através do aperfeiçoamento do uso da informação. Busca-se simplificar a aplicação dos conceitos utilizados e sinalizar a importância de atender às expectativas do consumidor através da troca de informações entre a equipe de produto e a área comercial.

\section{Agradecimentos}

Parte deste estudo foi financiado com apoio da CAPES (Coordenação de Aperfeiçoamento de Pessoal de Nível Superior).

\section{Referências}

BACK, N. et al. Projeto integrado de produtos: planejamento, concepção e modelagem: xxvi Ed. Barueri: Manole, 2008.

BURSTEIN, M. H.; DILLER, D. E. A framework for dynamic information flow in mixedinitiative human/agent organizations. Applied Intelligence, v. 20, n. 3, p. 283-298, 2004. 
CIETTA, E. A economia da moda. São Paulo: Estação das Letras e Cores, 2019.

CUNHA, I. B. de A.; PEREIRA, F. C. M.; NEVES, J. T. de R. Análise do fluxo informacional presente em uma empresa do segmento de serviços de valor agregado (SVA): Brapci 2.0. Pesquisa Brasileira em Ciência da Informação e Biblioteconomia; Vol. 11, N 1 (2016), v. 24, n. 2, 2018.

DURUGBO, C. et al. Information channel diagrams: an approach for modelling information flows. Journal of Intelligent Manufacturing, v. 23, n. 5, p. 1959-1971, 2012.

DURUGBO, C.; TIWARI, A.; ALCOCK, J. R. Modelling information flow for organisations: A review of approaches and future challenges. International journal of information management, v. 33, n. 3, p. 597-610, 2013.

FINARDI, C. O Fluxo da informação no processo de design de moda: uma análise aplicada em pequenas empresas de confecção da Grande Florianópolis. Universidade Federal de Santa Catarina, Florianópolis, 2011.

IEMI (Inteligência de Mercado). ABIT Associação Brasileira da Indústria Têxtil e de Confecção; SENAI - CETIQT Centro de Tecnologia da Indústria Química e Têxtil. 2017. Brasil Têxtil 2017: Relatório setorial da Indústria Têxtil Brasileira. 17. ed. São Paulo: IEMI Inteligência de Mercado.

JAUREGUI-BECKER, J. M.; WITS, W. W. An information model for product development: a case study at PHILIPS Shavers. Procedia CIRP, v. 9, p. 97-102, 2013.

LAKATOS, E. M.; MARCONI, M. A. Fundamentos de metodologia científica. 7. ed. São Paulo: Revista Produção Online, 2014.

LIBÂNIO, C. de S.; AMARAL, Fernando Gonçalves. A design management framework for the fashion industry. BBR. Brazilian Business Review, v. 14, n. 1, p. 1-20, 2017.

MORAES, G. D. de A.; ESCRIVÃO FILHO, E. A gestão da informação diante das especificidades das pequenas empresas. Ciência da informação, v. 35, n. 3, p. 124-132, 2006.

MORETTI, I. C. Proposta de um modelo de referência para o processo de desenvolvimento de produto do vestuário. Universidade Tecnológica Federal do Paraná, Paraná, 2012.

MORGAN, J. M.; LIKER, J. K. Sistema Toyota de desenvolvimento de produto: integrando pessoas, processos e tecnologia. Porto Alegre: Bookman Editora, 2008.

PARRAGUEZ, P.; EPPINGER, S. D.; MAIER, A. M. Information flow through stages of complex engineering design projects: a dynamic network analysis approach. IEEE Transactions on Engineering Management, v. 62, n. 4, p. 604-617, 2015.

RECH, S. R. Cadeia produtiva da moda: um modelo conceitual da análise da competitividade no elo confecção. Universidade Federal de Santa Catarina, Florianópolis, 2006.

RODRÍGUEZ, A.; FERNÁNDEZ-MEDINA, E.; PIATTINI, M.. A BPMN extension for the modeling of security requirements in business processes. IEICE transactions on information and systems, v. 90, n. 4, p. 745-752, 2007.

ROUBELAT, F. et al. Probing ephemeral futures: Scenarios as fashion design. Futures, v. 74, p. 27-36, 2015.

SHANKAR, R. et al. A collaborative framework to minimise knowledge loss in new product development. International Journal of Production Research, v. 51, n. 7, p. 2049-2059, 2013.

SIM, S. K.; DUFFY, A. H. Towards an ontology of generic engineering design activities. Research in Engineering Design, v. 14, n. 4, p. 200-223, 2003.

TONOLLI JÚNIOR, E. J.; BRODBECK, Â. F.; COSTA, C. A. Análise das relações dos elementos de alinhamento estratégico entre negócio e tecnologia da informação com o 
processo de desenvolvimento de produto. RAM. Revista de Administração Mackenzie, v. 13, n. 2, p. 135-170, 2012.

TREPTOW, D. Inventando moda: planejamento de coleção. 5. ed. São Paulo: Edição da Autora, 2013.

\section{Sobre os autores}

Letícia Cunico é professora do Instituto Federal de Educação Ciência e Tecnologia de Santa Catarina. Bacharel em Moda pela Universidade do Estado de Santa Catarina (UDESC), MBA em Gestão Empresarial pela Fundação Getúlio Vargas (FGV) e mestra em Administração pela Universidade Federal de Santa Catarina (UFSC). Conduz as atividades de suporte às empresas juniores do IFSC, coordenadora de extensão e eventos, membro do grupo de pesquisa MGDP. E-mail: leticia.cunico@ifsc.edu.br

Claudelino Martins Das Junior é Professor do Departamento de Ciências da Administração (CAD) e do Programa de Pós-Graduação em Administração (PPGA) da Universidade Federal de Santa Catarina (UFSC). Coordena o recém-criado grupo de pesquisa MGDP (Modelagem em Gestão, Design e Processos) e tem como principais objetos de pesquisa: simulação em gestão, desenvolvimento de produto/concepção de serviço e avaliação de desempenho.

E-mail: claudelino.junior@ufsc.br 